\title{
Population distribution, urban construction and urban management in the process of China urbanization
}

\author{
ZHANG Shu-jie \\ (School of Economics and Management, Tongji University, Shanghai 200092, China)
}

\begin{abstract}
Along with China's urbanization, a series of problems came, such as the rapidly expanding urban population, large-scale urban construction and investment, the financing gap of government's investment in construction, and urban management, etc. This article first describes the growth of urban population, the scale and the input of urban construction, and then analyzes the financial revenue and expenditure, and at last argues for the necessity of urban management, and puts forward the research content of urban management.
\end{abstract}

Key words: urban management; urbanization; financial revenue; population distribution and growth

\section{Introduction}

As China's urbanization process is to be still growing, a series of problems have been brought, such as the movement of millions of peasants to go to cities, the rapidly expanding urban population, large-scale urban construction, and other topics such as the investment in infrastructure in trillion as the unit of measurement, financial revenue and expenditure of all level government, and urban management. Firstly, this article describes the growth of urban population, the scale and input of urban construction, then analyzes the financial revenue and expenditure, and lastly researches on the necessity for urban management and systematically expounds the theory.

\section{Population movements and distribution with China urbanization}

\subsection{Population movement and distribution}

Since the reform and opening up, the level of China's urbanization has been improved, and the size and the number of towns have increased gradually. From 1978 to 2006, the level of urbanization increased from 17.92\% to $43.9 \%$, an annual increase of $0.93 \%$. By the end of 2006, there are 4 municipalities, 283 prefecture-level cities, 374 county-level cities, 852 municipal districts and 577 million urban populations in China. At present, China's urbanization process is mostly compatible with industrialization. The urban system is becoming better and approaching perfection day by day, which coordinates development of small towns and cities, medium-sized and large cities. Urbanization has become an important way to expand employment opportunities, achieve market expansion, ease the "three rural" issues pressure and promote new-type industrialization. Urban areas have gradually become the main spatial carriers for economic development and urban living environment has been greatly improved.

Experiencing 60 years' urban development, the urban development system has gradually become mature. A multi-level urban system in China has initially formed with large cities as the center, medium and small cities as

ZHANG Shu-jie, lecturer, School of Economics and Management, Tongji University; research fields: urban development and public management. 
the backbone, and small towns as the base. The feature of urban areas distribution from east to west is from dense to sparse. There are many mega-cities and large cities in the eastern part, and the small towns are intensive; The central region shows a more balanced distribution with many small towns; The urban population in the western region concentrated in large and medium cities. The densely developed areas of the Beijing and Tianjin, the Yangtze River Delta, Pearl River Delta, South Liaoning, Shandong Peninsula, west side of area, Jianghan Plain area, the Central Plains region, Chengdu and Chongqing region have initially formed in China. The new pattern becomes increasingly obvious, in which urban regional spatial acts as subject development and the big cities are the cores. The Yangtze River Delta, Pearl River Delta, and three city groups in Beijing, Tianjin and Hebei have made clearly. The fourth pole is in fierce competition.

According to the data of State Statistical Bureau, there are 665 national cities, 600 million urban populations in 2008. With the estimation by State Family Planning Commission, China's population will be 1,500 million by 2033. In accordance with the development trend of China urbanization at present, the urban population will be up to 926 million in 2025, with 66\% of the people living in the city. By 2030 the urban population will break through 1 billion. More than $80 \%$ of the national population will live in the city till 2050 . The total quantity of the urban population will reach 1.3 billion.

\subsection{Task of urban construction}

The scale of urban increases with the increase of urban population. In the coming 30-40 years, if we set the average density of urban population as $1 \mathrm{sq} \mathrm{km} /$ million per people, then we may find that:

(1) $1.4 \%$ of the land area will be used for urban construction. $15 \%$ of the land area (18 million mu of arable land) will be used for basic farmland;

(2) To accommodate future new citizens, 40 billion square meters of floor space are expected to be built, equivalent to 2-5 million units of more than 30-story skyscraper, which can be comparable to 10 times the number of buildings in New York City. According to McKinsey’s report, 221 large cities with over one million population and 23 the mega-cities with 5 million people will be built in China by 2025, and 8 mega-city of more than 10 million people will be built, such as Beijing, Shanghai, Guangzhou, Shenzhen, Tianjin, Wuhan, Chongqing and Chengdu, in which $41 \%$ of high-income group with a income of more than 40,000 CNY will be living;

(3) If the average intensity of investment in urban infrastructure is 300 million yuan $/ \mathrm{km}$, the government's total investment in newly constructed and renovated urban infrastructure projects will be 3.9 trillion yuan. Since the task of urban construction is so arduous, almost all urban governments are facing with the shortage of funds, and how to raise funds becomes a hard issue for all the mayors.

\subsection{The central and local government financial revenue and expenditure}

According to the prediction of the Development Research Center of the State Council, the economy will increase with a sustained rapid growth in "eleventh five-year" period, and the annual economic growth rate will maintain about $8 \%$. If calculating based on a constant price (2000 prices), GDP aggregate at the end of "eleventh five-year” will reach around 2.4 trillion U.S. dollars, exceeding the GDP of Germany in 2000. The per capita GDP will be about 1,700 dollars. Compared with the "eleventh five-year" period, the economic growth from 2010 to 2020 will slow down, and the annual economic growth rate will remain around 7\%. By 2020, GDP will reach 4.8 trillion U.S. dollars, which is more than Japan's GDP in 2000. The per capita GDP will be up to 3200 U.S. dollars. By 2020, in accordance with the forecast that country's population will reach 1.45 billion, China's economic aggregate will reach 4.62 trillion U.S. dollars.

Taking a look at the government's revenue and expenditure, nation's financial revenue is 6.2 billion in 1950 
and that is 6.133 trillion yuan in 2008, increasing by 1,000 times in 60 years. It took only nine years to increase from 1 trillion to 6 trillion yuan. From the future growth in financial situation, the urban GDP occupies $75 \%$ of the country's total GDP in 2008, and it is predicted to be $95 \%$ in 2025. The proportion of the urban consumption to GDP is $25 \%$ in 2005 , which is expected to be $33 \%$ in 2025 , reaching at 21.7 trillion yuan. Therefore, the future financial growth is enormous.

From the aspect of expenditures, the state gradually increased the investment in compulsory education, medical care, social security and other social undertakings. Since 1998, when China announced to speed up the transformation of financial system from the "constructive type of finance" to "public finance", the proportion of capital spending in central financial expenditure is declining. The local city government has been facing a very high operation cost and welfare expenditures on public services, medical care, education, etc. By 2025, it may be 1.5 trillion. Thus, despite the fact that the central government fiscal revenue increased significantly year by year, on the contrary, finance capital investment in the basic construction is decreasing.

The fiscal revenue varies widely in the 2800 governments of counties level and 280 governments of city (prefecture) level. Most county-level governments can not operate relying on its finance, and it still needs help from higher authority. Investment in urban construction is almost entirely funding from extra-budgetary, specially from land finance.

\section{Urban management}

\subsection{Urban management presentation}

Under the above social background, in order to seek a breakthrough for urban construction projects, the local governments has done a lot of attempts on investment diversification, market-oriented operation and management of social-oriented, which cover almost all aspects of urban work. They contain not only funding for construction characterized by urbanization as well as oriented activities such as land management in rapid urbanization, but also the work with the distinguishing features-industrialization as involving in macro-policy, transformation of government functions, science and technology industrial policy, urban planning work in steady urbanization. For such practical activities, government officials directly coined the term of "management" from enterprise, which is simply called as the urban management.

In recent years, with the development and debate of urban management theory, the urban governments implement various forms of urban management practices in accordance with their understanding. In particular, Municipal Utility Franchise Management Measures made by the Ministry of Construction is in full operation on May 1, 2004, which not only speeds up the broken-up of the exclusive monopoly on governments' services, but also marks the promotion of urban management from national policy aspect, and confirms the legitimacy and maneuverability of urban management.

\subsection{Connotation of urban management}

There are many theoretical discussions on urban management, such as connotation, nature, subject, object, targets. Combing many scholars’ viewpoints and a large number of practical activities, "urban management” can be defined as: It is a strategy and behavior way of urban government to achieve sustainable urban development based on urban development strategies; It is a market operation mode using the market mechanism, fully digging up and rationally exploiting resources, organizing resources, assets, capital, funds; It is a development concept in optimizing industrial development and urban construction with the purpose of enhancing the city's overall 
functionality, comprehensive competitiveness, as well as improving the living environment.

The tangible and explicit resources, such as land, infrastructure, etc, can be managed as the object of urban management. At the same time, the recessive resources can also be managed such as the government policy, the urban planning right, etc. However, a lot of things can't be managed in urban, such as disaster prevention facilities. In fact, levees, and so on, can only be properly managed.

The main purport of proposing the concept- “urban management”, is to break through the traditional thinking mode of "urban administration" and to achieve the expected targets more effectively using the new idea and mode of "management". Meanwhile, the "urban administration" is still valuable, but needs continuous development and constant change, in order to complement with "urban management" and develop together. Therefore, the issue needed to be solved in future urban development is that how to integrate the new forms.

\subsection{Research contents of urban management}

The main points of urban management are as following respects:

(1) Divide the stages of urban management into fast development of the urbanization and steady development of urbanization, and then study the characteristics of each stage;

(2) Study the intension, main body and object of urban management, and propose a whole set of method and tactics of urban management;

(3) Based on these basic principles, make special urban management designs for infrastructure, public facilities and public services. Give managing methods and ideas respectively to guide the practice of urban management and regulate the actual operation of urban business activities;

(4) Analyze the mode of operating city, then give the refractory curve of investment and establish the model of investment cost and benefit analysis. Explore the restriction mechanism and evaluation system of operating, in order to be able to grasp the "degree" of liability in practice;

(5) Analyze the phenomenon of misunderstanding and alienation in the practice of urban management, and then explain the root causes of alienation of urban management as the theoretical aspect, in order to avoid recurring of misunderstanding and alienation.

\section{References:}

Philip Kotler \& Alan R. Andreasen. (2003). Strategic marketing for nonprofit organization (5th ed.). Renmin University of China Press.

E. S. Savas. (2003). Privatization and public-private partnerships. Renming University of China Press.

Dennis A Rondinelli. (1998). Privatization, governance, and public management: The challenges ahead. Business and the Contemporary World, 10(2), 149-170.

Dnoald F. kettl. (2005). The global public management revolution. Washington, D. C: Brookings Institution Press.

Owen E. Hughes. (2004). Public management and administration: An introduction (3rd ed.). Renmin University of China Press.

Truman A. Hartshorn.( 1991). Interpreting the city: An urban geography (2nd ed.). John Wiley \& Sons, Inc.

ZHANG Shu-jie. (2006). Urban management theory and practice-doctoral dissertation.

NIU Wen-yuan. (2001). The report of China sustainable development strategy 2001. Science Press.

(Edited by Rudy and Chris) 